\title{
Numerical simulation of heavy oil flows in pipes using the core-annular flow technique
}

\author{
K. C. O. Crivelaro ${ }^{1}$, Y. T. Damacena ${ }^{1}$, T. H. F. Andrade ${ }^{2}$, \\ A. G. B. Lima ${ }^{1} \&$ S. R. Farias Neto ${ }^{2}$ \\ ${ }^{1}$ Mechanical Engineering Department, \\ Federal University of Campina Grande, Brazil \\ ${ }^{2}$ Chemical Engineering Department, \\ Federal University of Campina Grande, Brazil
}

\begin{abstract}
The importance of heavy oils in the world market for petroleum has increased very quickly in the last years. The reserves of heavy oils in the world are estimated at 3 trillion barrels, while reserves of light oils have reduced progressively in the last decade. The high oil viscosity creates major problems in the production and transportation of the oil. This situation leads to the high pressure and power required for its flow, overloading and damaging the equipment, increasing the cost of production. Due to the need to develop new alternatives that will make the production and transport of heavy oil economically viable, this work has the objective to study, numerically, the behavior of isothermal multiphase flow (heavy oil and water), type "core flow", in pipelines, using the software CFX 3 D. The pressure drop was determinated to a core-flow in a pipe with 7 in. diameter, 2.7 Pa.s oil viscosity and water at environment temperature. Results of the pressure, velocity and volume fraction distributions of the phases are presented and analyzed. It was verified that the pressure drop was reduced 58 times when compared to that obtained with oil flow alone in the pipe.
\end{abstract}

Keywords: heavy oil, numerical simulation, $C F X^{\circledR}$, two-phase flow oil-water. 


\section{Introduction}

The reserves of heavy oils in the world are estimated at 3 trillion barrels, while reserves of light oils have reduced progressively in the last decade. This leads to much economic interest in the reserves of heavy oils and research to make its production economically viable. The heavy oil has a low degree API (between $10^{\circ}$ and $22^{\circ}$ ) and high viscosity (between $100 \mathrm{cp}$ e $10000 \mathrm{cp}$ ). Besides, it has a high ratio of carbons/hydrogen, a large amount of residue carbon, asphaltenes, sulfur, nitrogen, heavy metal and paraffin. The major problems in heavy oil production are: high density, which increases the fluid hydrostatic weight, high viscosity, which makes the flow very difficult, resulting in high pressures and therefore high power being required for its flow, increasing the cost of production. In offshore fields, these difficulties become more serious due to the adverse conditions present during production and transportation. Nowadays, the methods currently used for heavy oil production are based on the reduction in the viscosity of the oil within the reservoir and well and, frequently, are associated with a system lift.

The core annular flow technique can be called core-flow; different to other techniques, it is based on the lateral injection of relatively small quantities of water into the pipe and is capable of generating an annular pattern of two-phase flow. This annular pattern will be very stable, since the two fluids are immiscible, where the oil is in center of the pipe and a thin layer of water is flowing near the wall surface. This injection of water will lubricate the wall of the pipe, reducing the friction between the wall and the oil along the flow, as reported by Prada and Bannwart [13] and Silva [14]. According to Bensakhria et al. [6], this technique was created by Isaacs and Speed in 1904, patent request $\mathrm{n}^{\circ}$ 759374 in the United States and was the first to mention the ability to transport viscous product through water lubrication. However, only in 1970 was a largescale industrial pipeline built (length of $30 \mathrm{~km}$ and diameter of $15 \mathrm{~cm}$ ) to transport heavy oil by the Shell Company near Bakersflield in California. For more than ten years, a viscous crude oil has been produced at the flow rate of $24000 \mathrm{bbl} / \mathrm{d}$ in a water lubricated regime.

The interest in heavy oil production employing the core annular flow technique has increased in recent years because of the large reserves of heavy oil accessible. This technique brings attractive results with regard to energy consumption. This fact is related to the reduction in pressure drop during the water/oil flow type core-annular when compared with the transport of oil alone (Andrade [1]). It has been observed in the literature related to the use of this technique to improve the transport of heavy oils using water as lubricant (Andrade [1]; Bai [3]; Bannwart [4]; Bensakhria et al. [6]; Joseph et al. [7]; Ko et al [8]; Oliemans et al. [9]; Ooms and Poesio [10]; Prada and Bannwart [13]). Bannwart [4] proposed a theory to stabilize the pattern annular when two liquids of density and viscosity flow differently in a horizontal pipe. The theory is based on the analysis of the linear momentum equation in a cross section of the pipe leading to account for the effect of interfacial tension. Bensakhria et al. [6] evaluated the radial position of the annular flow and showed that the position 
depends only on the relationships between the contact perimeter of the wall of the pipe and the fluid that forms the core (oil) and the perimeter of the pipe. This ratio depends on the difference in density between the fluids to transport and the fluid to lubricate, as well as of the amount of injected water.

The ideal annular flow or perfect core annular flow (PCAF) corresponds to an exact solution of the concentric fluid flow with a different density and viscosity in a pipe of circular cross section. According to Bensakhria et al. [6], the ideal or perfect annular flow appears to be very rare and can exist only for density matched fluid. Prada and Bannwart [13] also study a simplified solution to perfect annular flow, where two immiscible Newtonian fluids (oil and water) are flowing in a vertical pipe in a concentric configuration with a smooth circular interface. According to Prada and Bannwart [13], core flow lift is a new alternative for heavy oil production, because it significantly increases the well productivity by decreasing of the frictional pressure losses, without the addition of heat and without the use of chemical agents or diluents. Hence, artificial lift technology can be applied in either onshore or offshore fields, horizontal or vertical wells, and its installation in the field is relatively simple.

Ooms and Poesio [10] analyzed the annular flow in a stationary regime in a horizontal pipe and proposed a theoretical model based on hydrodynamic lubrication theory. According to this model, a harmonic motion was observed in the annular flow. Indeed, the more viscous fluid (heavy oil) is moved to a wave form in the center of the horizontal pipe; this behavior is known as Wavy Core Annular Flow (WCAF). Ooms et al. [11] theoretically investigated the hydrodynamic counterbalancing of buoyancy force on a core of heavy oil flowing in the pipe, by considering the difference in density between two fluids. During the study it was assumed that the fluid that forms the core consists of a solid center surrounded by a high-viscosity liquid layer. To represent the pressure drop correctly it was necessary to model the effects of the WCAF, such as turbulence and fluctuability. The buoyancy term favors the heavy oil flow, but this is affected by the wave interface in the two-phase flow water/heavy oil (Prada and Bannwart [13]).

In this sense the aims this work are to study, by numerical simulation, the isothermal behavior of the two-phase flow (oil and water) type core-flow of ultra-viscous heavy oils in pipe, using the finite-volumes method through the software $\mathrm{CFX}^{\circledR} 3 \mathrm{D}$. Through these simulations, the pressure, velocity and volume fraction distributions of the phases present will be analyzed.

\section{Methodology}

\subsection{Mathematical modeling}

The set of equations to be solved by $\mathrm{CFX}^{\circledR}$ are as follows. Continuity:

$$
\frac{\partial}{\partial t}\left(f_{\alpha} \rho_{\alpha}\right)+\nabla \bullet\left(f_{\alpha} \rho_{\alpha} \vec{U}_{\alpha}\right)=S_{M S \alpha}+\sum_{\beta=1}^{N_{P}} \Gamma_{\alpha \beta}
$$


Momentum equation:

$$
\begin{aligned}
& \frac{\partial}{\partial t}\left(f_{\alpha} \rho_{\alpha} \vec{U}_{\alpha}\right)+\nabla \bullet\left[f_{\alpha}\left(\rho_{\alpha} \vec{U}_{\alpha} \otimes \vec{U}_{\alpha}\right)\right]=-f_{\alpha} \nabla p_{\alpha}+\nabla \bullet\left\{f_{\alpha} \mu_{\alpha}\left[\nabla \vec{U}_{\alpha}+\left(\nabla \vec{U}_{\alpha}\right)^{T}\right]\right\}+ \\
& +\sum_{\beta=1}^{N}\left(\Gamma_{\alpha \beta}^{+} \vec{U}_{\beta}-\Gamma_{\beta \alpha}^{+} \vec{U}_{\alpha}\right)+S_{M \alpha}+M_{\alpha}
\end{aligned}
$$

where $\alpha$ and $\beta$ represent the phases involved (water or oil), $f$ is the volume fraction, $\rho$ is density, $\vec{U}$ is the velocity vector, $\mathrm{N}_{\mathrm{p}}$ is the number of phases involved, $p$ is the pressure and $\mu$ is viscosity. In addition, the term $\mathrm{S}_{\mathrm{MS} \alpha}$ describes user specified mass sources, $\Gamma_{\alpha \beta}$ is the mass flow rate per unit volume from phase $\beta$ to phase $\alpha, \mathrm{S}_{\mathrm{M} \alpha}$ describes momentum sources due to external body forces (buoyancy force and rotational force), $\mathrm{M}_{\alpha}$ describes the interfacial forces acting on phase $\alpha$ due to the presence of other phases (drag force, lift force, wall lubrication force, virtual mass force and interphase turbulent dispersion force), and the term $\Gamma_{\alpha \beta}^{+} \vec{U}_{\beta}-\Gamma_{\beta \alpha}^{+} \vec{U}_{\alpha}$ represents momentum transfer induced by interphase mass transfer.

To simplify the model and the governing equations solution, some consideration were assumed (table 1).

The following boundary conditions were used:

a) oil:

$$
\begin{aligned}
& \mathrm{u}=\mathrm{v}=0 \text { and } \mathrm{w}=U_{o} \text { in } \mathrm{z}=0 \text { to } \forall(\mathrm{x}, \mathrm{y}) ; \\
& \mathrm{u}=\mathrm{v}=\mathrm{w}=0 \text { to } \forall(\mathrm{x}, \mathrm{y}, \mathrm{z}) / \mathrm{x}^{2}+\mathrm{y}^{2}=\mathrm{r}^{2}, \text { where " } \mathrm{r} \text { " represents the radius }
\end{aligned}
$$
of the pipe.

Laminar flow regime.

b) water:

$$
\begin{aligned}
& \mathrm{u}=\mathrm{v}=0 \text { e } \mathrm{w}=U_{w} \text { em } \mathrm{z}=0 \text { para } \forall(\mathrm{x}, \mathrm{y}) \\
& \mathrm{u}=\mathrm{v}=\mathrm{w}=0 \text { para } \forall(\mathrm{x}, \mathrm{y}, \mathrm{z}) / \mathrm{x}^{2}+\mathrm{y}^{2}=\mathrm{r}^{2} ; \\
& \text { Turbulent flow regime. }
\end{aligned}
$$

The turbulence model used to water flow was the k-Epsilon model. In this model it is assumed that Reynolds stresses are proportional to the average velocity gradient, with the constant of proportionality characterized by turbulent viscosity (known as the hypothesis of Boussinesq).

Table 1: $\quad$ Considerations adopted for solving the governing equations.

\begin{tabular}{|l|l|}
\hline \multicolumn{2}{|c|}{ Consideration } \\
\hline Flow & $\begin{array}{l}\text { Two-phase (water/oil), tridimensional, } \\
\text { incompressible and isothermal. }\end{array}$ \\
\hline thermal-physical properties & constant \\
\hline Interphase transfer models & Mixture model \\
\hline Buoyancy force & Not considered \\
\hline Mass convergence criteria & $10^{-7} \mathrm{~kg} / \mathrm{s}$ \\
\hline Advection scheme & High resolution \\
\hline Pressure interpolation type & Trilinear \\
\hline Velocity interpolation type & Trilinear \\
\hline
\end{tabular}


The transport equations to turbulent kinetic energy, k, eqn. (3), turbulent dissipation, $\varepsilon$, eqn. (4), are:

$$
\begin{aligned}
& \frac{\partial\left(\rho_{\varepsilon} f_{\alpha} k_{\alpha}\right)}{\partial t}+\nabla \bullet\left\{f_{\alpha}\left[\rho_{\alpha} \vec{U}_{\alpha} k_{\alpha}-\left(\mu+\frac{\mu_{t \alpha}}{\sigma_{k}}\right) \nabla k_{\alpha}\right]\right\}= \\
& =f_{\alpha}\left(G_{\alpha}-\rho_{\alpha} \varepsilon_{\alpha}\right) \\
& \quad \frac{\partial\left(\rho_{\varepsilon} f_{\alpha} \varepsilon_{\alpha}\right)}{\partial t}+\nabla \bullet\left\{f_{\alpha} \rho_{\alpha} \vec{U}_{\alpha} \varepsilon_{\alpha}-\left(\mu+\frac{\mu_{t \alpha}}{\sigma_{\varepsilon}}\right) \nabla \varepsilon_{\alpha}\right\}= \\
& =f_{\alpha} \frac{\varepsilon_{\alpha}}{k_{\alpha}}\left(C_{1} G_{\alpha}-C_{2} \rho_{\alpha} \varepsilon_{\alpha}\right)
\end{aligned}
$$

where $G_{\alpha}$ is the generation of turbulent kinetic energy inside the phase $\alpha$ and $C_{1}$ and $C_{2}$ are empirical constants. In eqn. (5), $\varepsilon_{\alpha}$ is the rate of dissipation of the turbulent kinetic energy of the phase $\alpha$, eqn. (6), defined by:

$$
\varepsilon_{\alpha}=\frac{{ }^{c} \mu q_{\alpha}^{3}}{l_{\alpha}}
$$

and $k_{\alpha}$ is the turbulent kinetic energy to phase $\alpha$ given by:

$$
k_{\alpha}=\frac{q_{\alpha}^{2}}{2}
$$

where $l_{\alpha}$ is the spatial scale length, $q_{\alpha}$ is the scale of velocity and $c_{\mu}$ is an empirical constant calculated by eqn. (7), given by:

$$
c_{\mu}=4 c_{\alpha}^{2}
$$

In this equation $c_{\alpha}$ is an empirical constant and $\mu_{t \alpha}$ corresponds to turbulent viscosity, defined by eqn. (8) as follows:

$$
\mu_{t \alpha}=c_{\mu} \rho_{\alpha} \frac{k_{\alpha}^{2}}{\varepsilon_{\alpha}}
$$

The constant used in the eqns. (3)-(8) are: $C_{1}=1,44 ; C_{2}=1,92 ; c_{\mu}=0,09$; $\sigma_{k}=1,0 ; \sigma_{\varepsilon}=1,3$.

\subsection{Numerical solution}

The software CFX ${ }^{\circledR} 10$ was used to generate the mesh and numerical solution of the physical problem. This software uses the methodology of the finite volumes to solve its equations. The thermal-physical properties of the fluids and inlet velocity are illustrated in table 2. 
Table 2: $\quad$ The thermal-physical properties of the water and oil used in all simulations.

\begin{tabular}{|c|c|c|c|}
\hline & \multicolumn{2}{|c|}{ Thermal-physical properties } & \multirow{2}{*}{$\begin{array}{c}\text { Inlet velocity } \\
(\mathrm{m} / \mathrm{s})\end{array}$} \\
\hline & Density $\left(\mathrm{kg} / \mathrm{m}^{3}\right)$ & Viscosity (Pa.s) & \\
\hline $\begin{array}{c}\text { Water } \\
\text { Oil }\end{array}$ & $\begin{array}{l}997,00 \\
989,00\end{array}$ & $\begin{array}{c}0,0008899 \\
2,7\end{array}$ & $\begin{array}{l}1,0 \\
0,8\end{array}$ \\
\hline
\end{tabular}

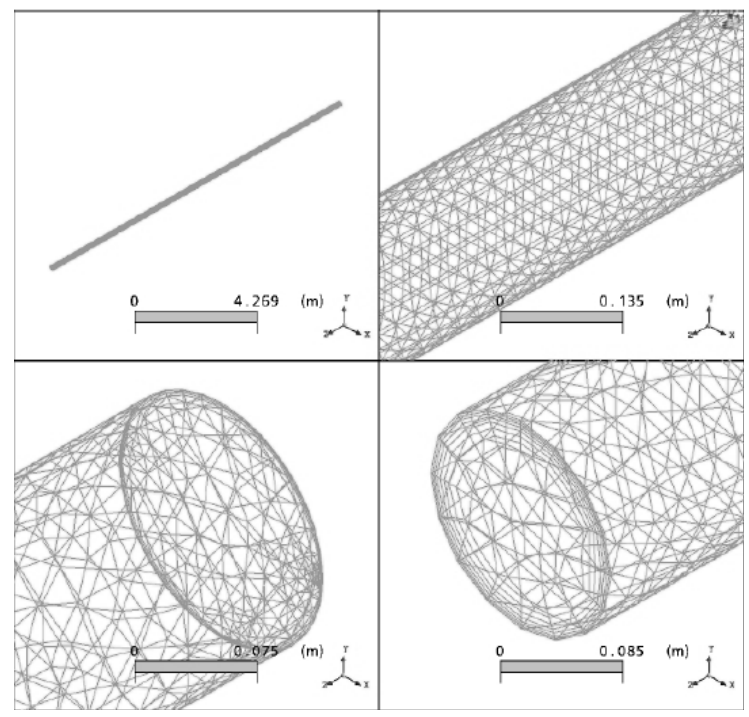

Figure 1: $\quad$ Numerical mesh used in all simulations.

For the initial condition, we considering that the pipe is full with water, and has a null vector velocity $\left(\mathrm{V}_{x \text { water }}=\mathrm{V}_{y \text { water }}=\mathrm{V}_{z \text { water }}=0 \mathrm{~m} / \mathrm{s}\right)$.

\subsection{Numerical mesh}

All the simulations were developed in the Thermal and Fluids Computational Laboratory, Mechanical Engineering Department, in the Center of Science and Technology of the Federal University of Campina Grande. The development of the mesh was a simplification of a nozzle reported by Prada and Bannwart [12]. The domain of study was created by definition of the points, curves, surfaces and solids and by describing the size and shape $(\mathrm{D}=0,1778 \mathrm{~m}$ e $\mathrm{L}=15 \mathrm{~m})$ of the nozzle, so we generate the unstructured mesh and after several refinements we obtain a mesh with 105700 elements as illustrated in fig. 1.

\section{Numerical results}

The numerical results, in the transient state, were obtained for an elapsed time of $\mathrm{t}=90 \mathrm{~s}$ and time steps of $\Delta \mathrm{t}=0.3 \mathrm{~s}$. In the steady state, we analyze the volume fraction, pressure field and velocity profiles. 
Fig. 2 shows the pressure drop in different positions along the length of the pipe ( $\mathrm{z}$ axis). A decrease of pressure along of the pipe is verified, with the highest pressure in the inlet and the lowest in the outlet of pipe. A pressure drop $\Delta \mathrm{p}=675.23 \mathrm{~Pa}$ was found, this being necessary to dislocate the oil and water. No gravity effects were considered. The mass flow rate of the oil and water were $15.86 \mathrm{~kg} / \mathrm{s}$ and $4.69 \mathrm{~kg} / \mathrm{s}$, respectively.

Figs. 3 and 4 show the volume fractions profile of the oil in the center. It is observed that the oil flows almost in central region of the pipe; approximately $95 \%$ of the center of the pipe is full of oil.

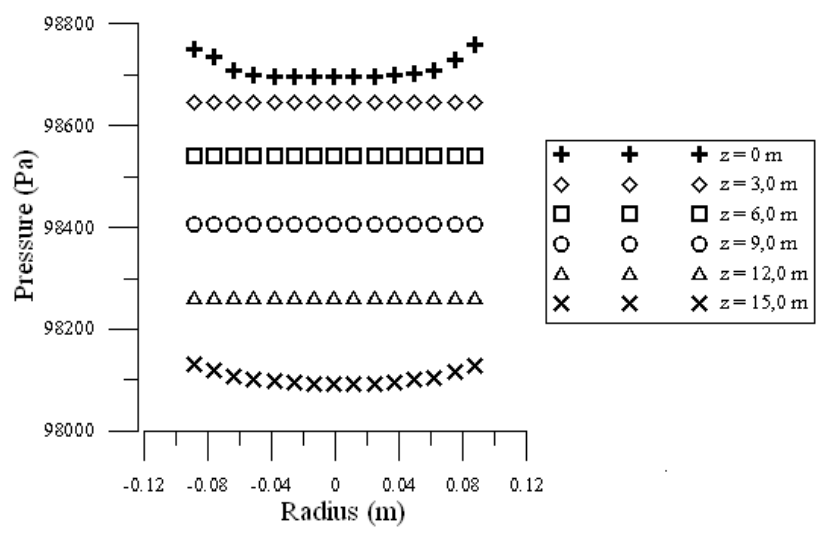

Figure 2: $\quad$ Pressure drop of the core flow as a fraction of the radial position for different locations along the pipe.

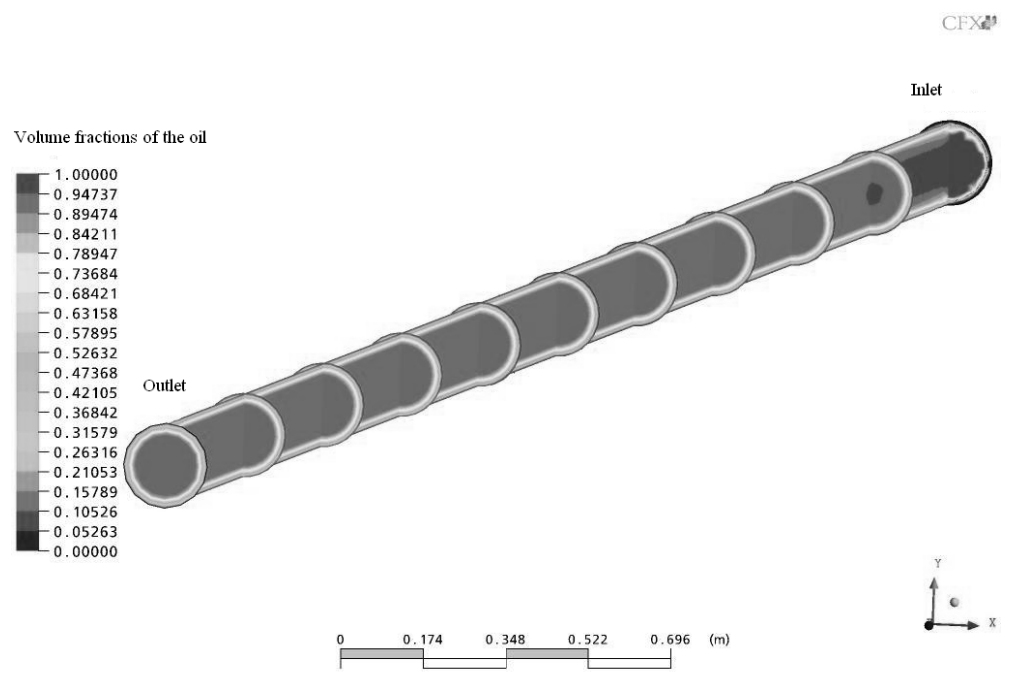

Figure 3: Volumes fractions of the oil in the core-flow along the pipe. 


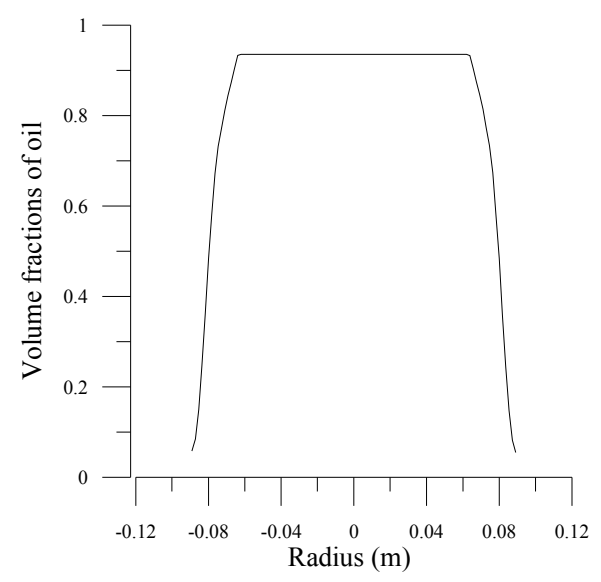

Figure 4: Volume fractions of the oil as a function of the radial position in $\mathrm{z}=7.5 \mathrm{~m}$.

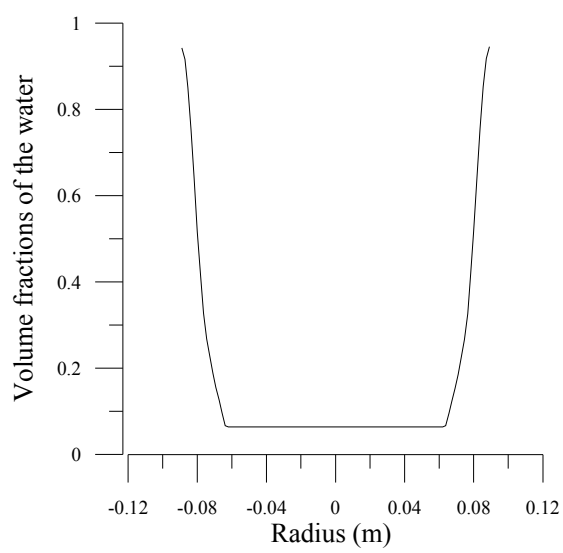

Figure 5: Volume fractions of the water as a function of the radial position in $\mathrm{z}=7.5 \mathrm{~m}$.

The volume fractions of the water in a steady state in different regions of the pipe are shown in fig. 5. As expected, the water moves near the wall of the pipe in the form of a ring. In addition, in fig. 5, we observe that a small portion of the water moves together with the oil in the center of the pipe $(\approx 5 \%)$. This can be justified by the occurrence of dispersion of the water phase in the center of the pipe due to the turbulence level of the flow.

The oil velocity profiles along of the pipe are shown in fig. 6. A small region, the so called hydrodynamic entrance length, where the fluid moves with constant velocity profiles along the pipe, is verified. 


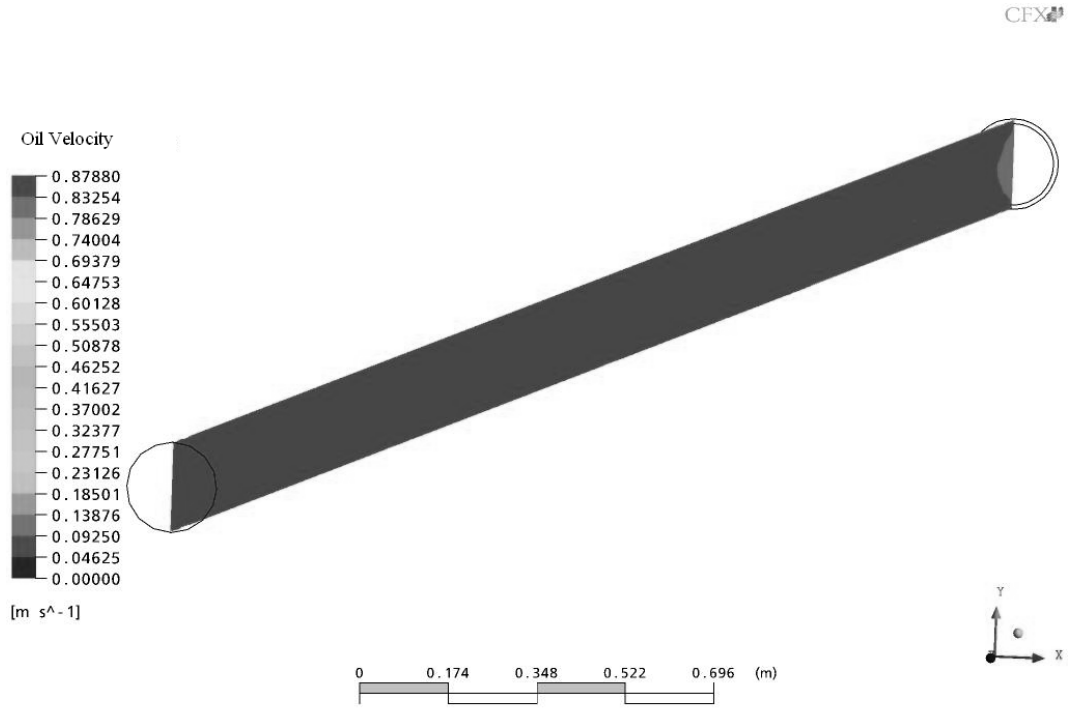

Figure 6: Oil velocity profiles in a core-flow along the pipe.

Table 3: $\quad$ Comparison of the pressure drop among water and oil single-phase flow and core annular flow.

\begin{tabular}{|c|c|c|}
\hline Flow & Pressure drop (Pa) & $\begin{array}{l}\text { Reduction } \\
\text { factor }(\Omega)\end{array}$ \\
\hline $\begin{array}{c}\text { Core-flow } \\
\text { Water single-phase flow } \\
\text { Oil single-phase flow }\end{array}$ & $\begin{array}{c}675.23 \\
539.52 \\
39112.18 \\
\end{array}$ & 57,2 \\
\hline
\end{tabular}

The oil velocity profiles in a pattern core-flow stay almost constant in the center of the pipe until the annular region, where a water fraction of $5 \%$ can be seen in fig. 7. In the wall, the water velocity profiles were made null by increasing the distance of the wall until the region is found where the oil flows alone, see fig. 7 .

To evaluate the efficiency of the core-flow technique, we compare the pressure drop in the two-phase flow with the pressure drop obtained in the water and oil single-phase flow. The water in the core flow is always in contact with the internal wall of the pipe and the pressure drop in the two-phase flow should be close to the pressure drop in the water flow alone at the mass flow rate of the mixture (Barbosa [5]). Table 3 shows this pressure drop. It was necessary for $\Delta \mathrm{p}$ $=539.52 \mathrm{~Pa}$ to move a water flow rate of $\dot{m}_{w}=20.6 \mathrm{~kg} / \mathrm{s}$ along the pipe, without considering the effects of gravity. This pressure drop was lowest at the value obtained in the core-flow $(\Delta \mathrm{p}=675.22 \mathrm{~Pa})$. This demonstrates that through this method, we can move ultra-viscous petroleum with a pressure drop near to the value found in water flow. The pressure drop in the case of the single-phase flow 


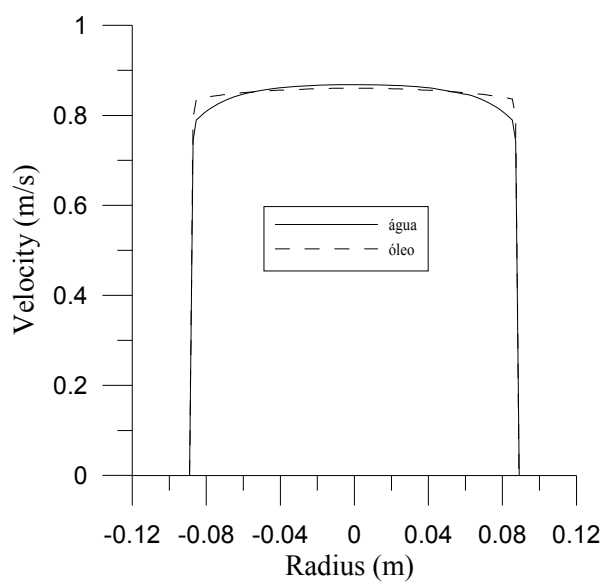

Figure 7: Velocity profiles of the water and oil in the center of the pipe as a function of the radial position.

of oil is introduced in fig. 7. It was necessary for $\Delta p=39112.1 \mathrm{~Pa}$ to move an oil flow rate of $20.44 \mathrm{~kg} / \mathrm{s}$ along the pipe. By comparing the $\Delta \mathrm{p}$ of the cases coreflow, a reduction factor of the pressure drop of approximately 58 times was obtained.

\section{Conclusions}

In this work a numerical study of the phenomenon associated with water-oil twophase flow of the core-flow type was developed. Results of the velocity, pressure and volume fraction of the phases were obtained, analyzed and compared, by showing the efficiency of the core-flow technique in the production and transport of heavy oils. In this study, it can be concluded that $\Delta \mathrm{p}=676.17 \mathrm{~Pa}$ was necessary to move the heavy oil in a core-flow, in a pipe of 7 inch diameter and $15.0 \mathrm{~m}$ length. The mass flow rate of oil and water were $15.85 \mathrm{~kg} / \mathrm{s}$ and 4.68 $\mathrm{kg} / \mathrm{s}$, respectively. By comparing the core-flow technique with a water singlephase flow, we notice that the two-phase pressure drop $(\Delta \mathrm{p}=676.17 \mathrm{~Pa})$ approaches the pressure drop in water single-phase flow $(\Delta \mathrm{p}=501.5 \mathrm{~Pa})$ to oil viscosity of 2.7 Pas. By comparing the core-flow technique with an oil singlephase flow, the reduction factor of the pressure drop was approaching 58 times. Due to these benefits, we observe great interest in the use of the core-flow technique to solve the problems related to the production and transport of ultraviscous oil in pipes.

\section{References}

[1] Andradre, T. R. F. Numerical study of heavy oils transport on pipe lubrificated by water. Master thesis in Chemical Engineering - Federal University of Campina Grande, Paraíba, Brazil, 2008. 
[2] ANSYS, CFX-Theory Manual, 2005.

[3] Bai, R. Traveling waves in a high viscosity ratio and axisymmetric core annular flow. PhD Thesis, Faculty of Graduate School of the University of Minnesota, Minnesota-USA, 1995.

[4] Bannwart, A. C. Modeling aspects of oil-water core annular flows, Journal of Petroleum Science and Engineering, vol., 32, pp. 127-143, 2001.

[5] Barbosa, A. Transient effects in the pressure drop for heavy oil-water core annular flow in metallic pipes. Master thesis in Petroleum Engineering State University of Campinas, Campinas, 2004

[6] Bensakhria, A.; Peysson, Y. \& Antonini, G., Experimental study of the pipeline lubrication for heavy oil transport. Oil \& Gas Science and Technology - Rev. IFP, vol. 59, N. 5, pp. 523-533, 2004.

[7] Joseph, D. D., Bai, R., Chen, K. P. \& Renardy, Y. Y., Core annular flows. Annual Reviews Fluid Mechanical, vol. 29, pp.65-90 1997.

[8] Ko, T.; Choi, H. G.; Bai, R. \& Joseph, D.D. Finite element method simulation of turbulent wavy core annular flows using a $k$-w turbulence model method. International Journal of Multiphase Flow, vol. 28, $\mathrm{N}^{\mathrm{o}} 7 \mathrm{pp}$. 1205-1222, 2002.

[9] Oliemans, R.V.A.; Ooms, G.; Wu, H.L. \& Duijvestijn. A., The core annular oil/water flow turbulent-lubricating-film model and measurements in a 5 $\mathrm{cm}$ pipe loop. International Journal of Multiphase Flow, vol. 13, №. 1, pp. 23-31, 1987.

[10] Ooms, G. \& Poesio, P., Stationary core-annular flow through a horizontal Pipe. Physical Review, vol. 68, 2003.

[11] Ooms, G.; Vuik, C. \& Poesio, P., core-annular flow through a horizontal Pipe: hydrodynamic counterbalancing of buoyancy force on core. Physics of Fluids, vol. 19, № 092103 (2007).

[12] Prada, J. W. V. \& Bannwart, A. C. Pressure drop in vertical core annular flow, XV Brazilian Congress $f$ Mechanical Engineering, Água de Lindóia, São Paulo, 1999.

[13] Prada, J. W. V. \& Bannwart, A., C., Modeling of vertical core annular flows and application to heavy oil production. Energy for the New Millennium February 14-17, New Orleans, LA. Proceedings of ETCE/OMAE, 2000.

[14] Silva, R.C.R. Wettability alteration of internal surfaces of pipelines for used in the transportation heavy oil via core-flow. Master thesis in Science and Petroleum Engineering - State University of Campinas, São Paulo, 2003. 